\title{
CORRECTION
}

\section{Correction to: Production of poly hydroxy butyrate (PHB) from Eichhornia crassipes through microbial fermentation process}

\author{
Varsha Upadhayay, Shubhangee Soni, Samakshi Verma \& Arindam Kuila* \\ Department of Bioscience \& Biotechnology, Banasthali Vidyapith, Rajasthan 304 022, India \\ Article history \\ Correction request: 12 February 2020 \\ Published: 17 March 2020

\section{Publisher} \\ Horizon e-Publishing Group \\ ${ }^{*}$ Correspondence \\ Arindam Kuila \\ 凶arindammcb@gmail.com

\section{Citation} \\ Upadhayay V, Soni S, Verma S, Kuila A. Correction to: Production of poly \\ hydroxy butyrate (PHB) from Eichhornia crassipes through microbial \\ fermentation process. Plant Science Today 2020;7(1):135. \\ https://dx.doi.org/10.14719/pst.2020.7.1.782 \\ Copyright: (c) Upadhayay et al (2020). This is an open-access article distributed \\ under the terms of the Creative Commons Attribution License, which permits \\ unrestricted use, distribution, and reproduction in any medium, provided the \\ original author and source are credited \\ (https://creativecommons.org/licenses/by/4.0/).
}

\section{Correction to:}

Plant Science Today 6(sp1):541-550.

https://doi.org/10.14719/pst.2019.6.sp1.673

The authors regret the exclusion of Shubhangee Soni, Department of Bioscience \& Biotechnology, Banasthali Vidyapith, Rajasthan 304 022, India as one of the coauthors in the above mentioned original article.

The authors would like to apologise for any inconvenience caused.
The corrected Authors' contributions is given below:

\section{Authors' contributions}

First and second authors performed and analyzed all the experimental work. First and third authors wrote the manuscript. Corresponding author planned the work and revised the final manuscript. 